\title{
In a Lonely Place? Social Networks, Job Seeking and the Experience of Long-Term Unemployment
}

\section{Colin Lindsay}

Employment Research Institute, Edinburgh Napier University Business School

E-mail: c.lindsay@napier.ac.uk

Combating long-term unemployment remains a central strand of policies to promote social and labour market inclusion. One area of increasing concern is that the longterm unemployed (and especially those residing in disadvantaged communities) can find themselves isolated from the diverse social networks that can contribute to effective job seeking. This article draws on interviews conducted with 220 job seekers in two areas of high unemployment within the city of Glasgow to investigate: whether long-term unemployed people in these areas struggle to access social networks for job search; and the extent to which long-term unemployment is in itself associated with a more general erosion of social/community relations and a withdrawal from what has been termed the 'tertiary sphere of sociability.' The article concludes with a discussion of the potential role for social policy in seeking to help the long-term unemployed and other job seekers to develop and broaden social networks and activities.

\section{Introduction}

In recent years, policy makers and researchers have become increasingly interested in the role of social capital in facilitating job seeking and access to employment. A particular area of policy interest has been access to social networks among disadvantaged job seekers in inner-city areas characterised by high levels of unemployment and deprivation. Indeed, a number of innovative labour market polices have sought to promote strengthened social networks among the unemployed, while 'social capital building' has emerged as an important theme for regeneration strategies. Such approaches reflect an awareness that social networking can be vital to job search success and employability, but also concerns that the long-term unemployed in particular can fall victim to a more profound and serious form of isolation from normal social interactions and key social/community institutions - what is termed below 'the tertiary sphere of sociability' (Gallie et al., 2003). Experiencing such prolonged isolation may have negative consequences for individuals' employability, but also their broader well being and, cumulatively, social cohesion within local communities (Sinfield, 1968; Clasen et al., 1997).

This article seeks to contribute to this area of research by investigating the relationship between access to social networks for job seeking, sociability and the experience of longterm unemployment. ${ }^{1}$ Specifically, the article addresses three main issues: To what extent do long-term unemployed people in disadvantaged areas struggle to access the kind of social networks (i.e. contacts with people working in relevant occupations and sectors) that can potentially lead to more useful job search information? Is the experience of longterm unemployment in itself associated with a more general erosion of social/community 
relations and a withdrawal from the tertiary sphere of sociability? Is there a role for social policy in seeking to help the long-term unemployed and other job seekers to develop and broaden social networks and activities? The article is based upon 220 interviews undertaken with unemployed people residing in two areas of the city of Glasgow characterised by high levels of unemployment.

Following this introduction, the article reviews the context for the research by discussing the importance of social networks to employability and job seeking, and the relationship between long-term unemployment and social exclusion. The next section describes the study area and methodology. The findings from interviews are then presented, focusing on access to social networks for job seeking among the long-term unemployed people and other interviewees and the relationship between unemployment duration, job seeker characteristics and isolation from the tertiary sphere of sociability. We then review policies to strengthen the social networks of unemployed people and promote social capital building in disadvantaged communities, and discusses implications for future policy.

\section{Social networks, social exclusion and long-term unemployment}

\section{Social networks and job seeking}

Recent discussions of the concept of employability have emphasised the value of social capital (in the form of access to networks) in facilitating individuals' progress in the labour market (McQuaid and Lindsay, 2005). For Fugate et al. (2004: 24): 'Social capital is the goodwill inherent in social networks. [It] contributes an overtly social element to employability, and it confers information and influence to the 'holder' via networks.'

There is evidence that social networks can play an important role in transitions to work. Hannan (1999), using British Household Panel Survey data, demonstrates that that while unemployment duration, the use of formal search facilities and other factors impact upon exits from unemployment, access to social networks significantly affects job entry rates. Levesque and White's (2001) research with long-term welfare recipients in Canada supports this position - they argue that the range and diversity of social network resources available to the long-term unemployed can be the defining factor determining successful transitions to work, with a broad range of weak social network ties (i.e. acquaintances connected with the world of work rather than close friends or family) 'validating' the human capital of job seekers by providing access to references and good-quality vacancy information.

Earlier, it was Granovetter's $(1973,1982)$ seminal research on the job search strategies deployed by higher-skilled workers that highlighted the potentially crucial role of social networks. Granovetter noted the importance of the 'strength of ties' to job seeking, arguing that 'weak ties' (acquaintances, colleagues) provide more non-redundant information than do 'strong ties' (family and close friends). Research conducted since Granovetter introduced the idea of the importance of the strength of weak ties has similarly concluded that that the range and diversity of job seekers' networks affect their ability to locate employment (see Lai et al., 1998 for a review of evidence).

There are counter-arguments to the strength of ties hypothesis. Mouw (2003: 868) has suggested that no causal link can be identified between high levels of social network resources and job outcomes, instead arguing that the similarity between the 
status of individuals and their social ties is likely to explain any 'social capital effect' i.e. 'there is a tendency for similar people to become friends rather than a causal effect of friends' characteristics on labour market outcomes'. The homophily of social networks has similarly been acknowledged by other studies as representing an important methodological challenge to any research seeking to identify distinct causal relationships between networking and socio-economic status (McPherson et al., 2001).

Nevertheless, there remains clear evidence that effective social networking can facilitate transitions to (and within) work, and so at least reinforce individuals' labour market status and employability. People with access to diverse, work-based networks are generally more likely to locate a 'resource-rich' contact person, with greater potential to positively impact on job search outcomes (Lai et al., 1998). Network diversity and the heterogeneity of contacts can therefore be important to job search success, and so to the integration of potentially excluded groups, such as young people (Holzer, 1988), women returners (see Chapple's, 2002, US research) and ethnic minorities (see Ooka and Wellman's, 2006, research in Canada). Furthermore, it is clear that social networks, whatever their impact, are at least considered to be important by many job seekers, and appear to play a crucial role in regions where formal employment services are less advanced or less used by communities (Lindsay et al., 2005).

Long-term unemployment, area-based disadvantage and the tertiary sphere of sociability

The manner in which a lack of social network resources (and especially the absence of a diverse range of work-related contacts) can impact on employability also has a spatial dimension. Research undertaken in the US (Wilson, 1996) has pointed to the links between social network structure and poverty, with residents of 'segregated', disadvantaged urban areas finding the range and quality of their employment networks limited by poverty and social isolation. As Reingold's (1999) work in US cities notes, people in such disadvantaged urban areas can struggle to access 'vertical networks' that provide access to better jobs - this 'network poverty' (Perri 6, 1997) can severely limit individual opportunity.

Furthermore, it has been shown that the experience of long-term unemployment in particular, and the related restricted social contact and sense of exclusion experienced by some people (which can be particularly intense in disadvantaged urban areas), can in itself undermine confidence and reinforce geographical isolation. MacDonald et al.'s (2005: 884) work with young people in disadvantaged neighbourhoods in English cities finds that social networks tend to be strong, but tightly knit, based on close personal or family contacts, and limited to the immediate locality - the limited scope and range of social networks can 'close down' employment opportunities for young people, with their job search often 'proximate with the spatial reach of such networks'. Similarly, Hedstrom et al.'s (2003) research with urban job seekers in Sweden identifies the negative impact of restricted social networks (concentrated in disadvantaged areas) on exits from unemployment.

Gallie et al. (2003) explore a more specific relationship between what they call the 'tertiary sphere of sociability' and the experience of unemployment. Using EU-level data, they demonstrate that unemployed people are increasingly less likely to participate in organised social activity, through religious institutions, social/sports clubs or community organisations. Gallie et al. (2003: 28-29) suggest that limited access to the tertiary sphere 
of sociability is a function of pre-existing job seeker characteristics within specific social settings, rather than being caused by unemployment per se - but they are also clear that the social isolation experienced by some job seekers 'may seriously accentuate the psychological deprivations arising from unemployment'. Julkunen's (2002) research with young people in Scotland and Nordic countries more clearly identifies a relationship between long-term unemployment and a decline in activities within the tertiary sphere of sociability. What is clear is that where long-term unemployed people are excluded from this tertiary sphere of sociability (assuming that long-term unemployment may exacerbate such forms of isolation), there are potential implications for both the further erosion of social networks, and broader socio-psychological and mental health problems.

\section{The study}

Profile of the study areas

The research was carried out in Glasgow, Scotland's largest city (and the UK's fourth largest) with a working age population of approximately 370,000. At the time of the research, claimant unemployment was 4.8 per cent, compared to Scottish and UK figures of 3.2 per cent and 2.6 per cent respectively. However, claimant unemployment figures mask a more serious problem of pockets of long-term economic inactivity, with large numbers claiming non-work related benefits - at the time of the research more than 100,000 working-age residents of Glasgow were claiming benefits of some kind. Recent research has suggested that the 'real level of unemployment' (non-voluntary inactivity among those willing to work) within the city remains at 14 per cent, well above Scottish and UK averages (Beatty et al., 2007).

The research was carried out in two areas of Glasgow: Pollock in the south-west, and Springburn in the north of the city. Most interviewees resided in 'Social Inclusion Partnership' (SIP) areas within these localities (SIPs were, until recently, the Scottish Government's main targeted policy to address social exclusion in particularly deprived localities). Both areas reported above-average levels of unemployment and economic inactivity. Household surveys at the time of the research found that in the 'Greater Pollock SIP' area and the 'Springburn and East Balornock SIP' area (which contained the Springburn study area) only 32 per cent of 17-74 year olds were in work (compared with Scottish and Glasgow averages of 58 per cent and 47 per cent respectively). The same research found that 49 per cent of Greater Pollock and 65 per cent of Springburn adults held no formal qualifications, compared to 41 per cent of Glasgow adults, and 33 per cent of the Scottish population.

\section{Methodology and sample profile}

Structured, face-to-face interviews were carried out by the author with 220 claimant unemployed people at Jobcentre Plus offices in the two areas. ${ }^{2}$ Interviews were conducted in quiet areas near the front of offices, but well away from Jobcentre Plus staff, to ensure that interviewees felt confident when discussing sensitive issues. The sample accurately reflected the gender balance within the claimant unemployed population in Glasgow (80 per cent men and 20 per cent women). The age profile of the sample also reflected the wider claimant unemployed population reasonably accurately. However, 
Table 1 Percentage of interviewees using selected job search methods (\%)

\begin{tabular}{llll}
\hline \hline Job search method & $\begin{array}{l}\text { Unemployed } \\
<1 \text { year }\end{array}$ & $\begin{array}{l}\text { Unemployed } \\
\geq 1 \text { year }\end{array}$ & $\begin{array}{l}\text { All } \\
\text { interviewees }\end{array}$ \\
\hline Newspaper advertisements & 92 & 93 & 92 \\
Jobcentre Jobpoints & 69 & 56 & 65 \\
Jobcentre staff & 60 & 53 & 58 \\
Social networks (friends and family) & 55 & 47 & 53 \\
Direct approach** & $51^{* *}$ & $27^{* *}$ & 44 \\
Social networks (work-related)* & $45^{*}$ & $29^{*}$ & 40 \\
Community organisations & 14 & 11 & 13 \\
\hline \hline
\end{tabular}

Notes: ${ }^{* *}$ Significant difference at $1 \%$ level (Chi squared test). ${ }^{*}$ Significant difference at $5 \%$ level.

the long-term unemployed were deliberately over-represented, to ensure a usable sample for comparing the barriers faced by these and other job seekers. Approximately onethird of interviewees had been unemployed for more than one year, compared to 16 per cent of Glasgow's unemployed. The gender balance of the long-term unemployed group was identical to that of the overall sample. The long-term unemployed group did, however, have an older age profile (reflecting the concentration of older job seekers among the total long-term unemployed population in the city). In terms of the key 'individual factors' affecting job seekers' employability (McQuaid and Lindsay, 2005), there is evidence that those participating in this study faced significant barriers to work. For example, 37 per cent of interviewees held no qualifications, rising to 61 per cent among the long-term unemployed. Competing in a Scottish labour market where only 17 per cent of economically active people are similarly unqualified, these job seekers will be disadvantaged.

\section{Findings from interviews with job seekers}

\section{Social networks and job seeking}

A basic analysis of unemployed people's use of job search methods demonstrated that social networking played an important role, but was one search strategy among many. As Table 1 shows, more than 90 per cent of interviewees reported using newspaper advertisements to look for work on a regular (defined here as weekly) basis, while the majority also visited Jobcentres to use computerised 'Jobpoint' search databases and/or seek the advice of staff. However, social networking also emerged as an important tool, with 53 per cent using close friends and family and 40 per cent using work-related ties.

It is clear that the long-term unemployed among the sample were less connected with former colleagues and other (potentially more relevant) work-related network ties. Only 29 per cent of those unemployed for more than one year used such contacts for job seeking on a regular basis, compared to more than 45 per cent of those unemployed for less than a year (a difference significant at the 5 per cent level using chi squared test). ${ }^{3}$ Long-term unemployed people were also slightly less likely to use close family and friends to look for work, but the difference here was not significant. Indeed, among the few significant differences in job seeking between the long-term unemployed group and other interviewees were two potentially crucial aspects of informal search behaviour - the 
Unemployed less than one year

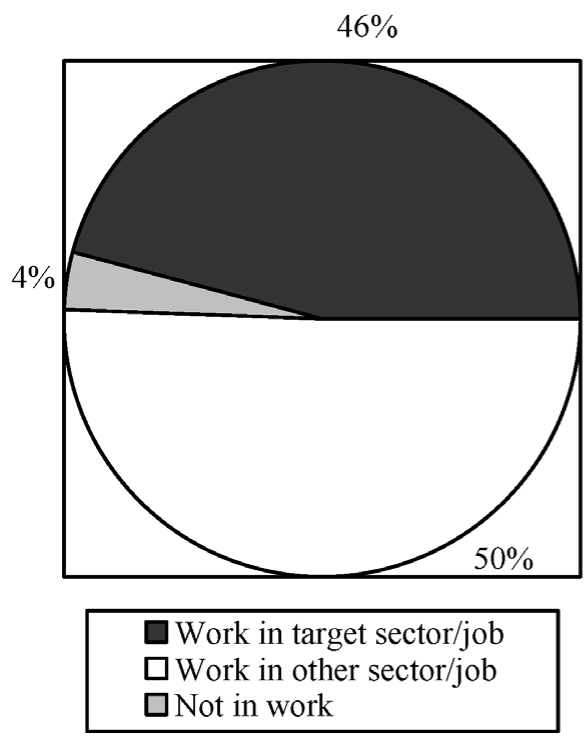

Unemployed one year or more

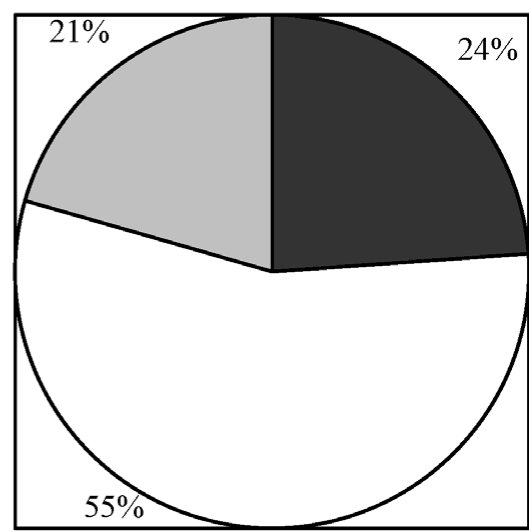

口Work in target sector/job $\square$ Work in other sector/job $\square$ Not in work

Figure 1. Employment status of 'main social network contacts' used for job search (\%).

use of work-related social networking and directly approaching employers (in the latter case the difference between the two groups was significant at the 1 per cent level using chi squared test).

If the strength of weak ties thesis has merit, then there may be cause for concern here. The majority of unemployed job seekers were not able to network with workrelated personal acquaintances on a regular basis, and long-term unemployed people in particular were excluded from this form of networking. Given the evidence that such work-related ties provide more valuable, 'non-redundant' job search information, a lack of access to such networks could reinforce the disadvantage experienced by the long-term unemployed.

Further probing of interviewees' perceptions of their own social networks confirmed that there were significant differences between the experiences of the long-term unemployed and other job seekers. First, long-term unemployed people were less likely to see networking as an important aspect of the job search process. Those who had been unemployed for less than one year were significantly more likely (5 per cent level using chi squared test) to consider using personal contacts to be 'very important' to looking for work (27 per cent of these more recent job seekers, compared with only 15 per cent of the long-term unemployed) - although it is also noticeable that relatively few job seekers in either group appeared to acknowledge the potential importance of networks. Second, the long-term unemployed were significantly more likely (1 per cent level using chi squared test) to report never having found out about a job through personal contacts (42 per cent of the long-term unemployed, compared to 24 per cent of other job seekers).

Finally, as Figure 1 illustrates, long-term unemployed people were less likely to have contacts in the same type of work (i.e. sector and/or occupation) that they were pursuing. Only 24 per cent of long-term unemployed people said that their main job search network 
ties - the contacts that they most often used for looking for work - were employed in the type of work that they were looking for, compared to 46 per cent of other job seekers (significant at the 1 per cent level using chi squared test). Of greater concern is that more than one-fifth of the long-term unemployed said that their main network contacts were themselves unemployed. In comparison, less than 5 per cent of other job seekers most often used other unemployed people for job search networking (the difference between the two groups was significant at the 1 per cent level using chi squared test).

\section{The experience of long-term unemployment and the tertiary sphere of sociability}

The same interviews with job seekers sought to probe the extent to which the experience of unemployment was linked with broader processes of social exclusion. Accordingly, the research involved a series of questions about job seekers' engagement in regular social activities. Long-term unemployed people were significantly less likely (5 per cent level) to report socialising on at least a weekly basis with friends/family (29 per cent, compared to 46 per cent of those unemployed for less than one year). Furthermore, although only just over one-fifth of all job seekers were involved in regular, organised social activity (what has been termed the tertiary sphere of sociability), there were again significant differences between the long-term unemployed and other job seekers. Only 11 per cent of long-term unemployed people reported being involved in such social activities (for example, attending a sports or social club) on a weekly basis, compared to 26 per cent of other job seekers - a difference significant at 1 per cent level using chi-squared test.

These data, taken together with the findings above on the regular job search activities of interviewees, highlight how long-term unemployment can contribute to a 'narrowing' of social life - as Sinfield (1981: 92) notes, there is a danger that the long-term unemployed 'tend to withdraw from society and to expect less'. A decreasing engagement in formal and informal sociability was clearly linked to the experience of unemployment (and the resulting loss of income and lack of daily contact with former colleagues and acquaintances) for many people. Many interviewees talked about how they had been less able to engage in social activity since losing their jobs, with long-term unemployed people particularly likely to raise these issues. Indeed, 46 per cent of all interviewees said that they socialised less as their period of unemployment grew (56 per cent of the long-term unemployed, compared to 42 per cent of other job seekers - a difference significant at 1 per cent level using chi squared test).

Gallie et al. (2003), reporting on European Household Panel Survey data, argue that declining access to the tertiary sphere of sociability is less to do with the experience of unemployment in itself than the initial, relative social isolation of some people in some communities even prior to becoming unemployed. But the (admittedly small) study reported above highlights the need for further research on how long-term unemployment in particular may accentuate the experience and impact of social isolation. This is not to say that being in the category 'long-term unemployed' in itself explains why certain job seekers were more likely to fall victim to these forms of social exclusion - rather, longterm unemployed people participating in this research faced multiple additional barriers to work, which were in turn often associated with more limited access to social capital. Compared to other interviewees, the long-term unemployed were statistically significantly more likely to: have few/no qualifications, consider their occupational skills to be less than 'good', think their job prospects to be poor and report work histories with little by 
way of stable employment - all job seeker characteristics that were also significantly associated with more limited access to social networks. The long-term unemployed were also more likely to report health problems.

Finally, it is important to note that those unemployed for one year or more were significantly more likely ( 1 per cent level using chi squared test) to live alone ( 51 per cent, compared to 31 per cent of other job seekers). Single occupancy in Glasgow is higher than the Scottish average ( 41 per cent and 33 per cent of the households respectively ${ }^{4}$ ) but these data suggest that long-term unemployed people are particularly likely to be alone important, given that there is evidence that living alone appears to reduce the chances of exiting unemployment (Gallie et al., 2003; Green and Owen, 2006). The long-term unemployed were also significantly less likely to have access to basic household resources such as a telephone and their own transport; and they often reported very low household incomes. More than half of the total sample reported a household income of less than $£ 100$ per week (53 per cent, rising to 62 per cent of long-term unemployed people). By way of comparison, a survey for Communities Scotland conducted near the time of the research concluded that only 9 per cent of Glasgow households had a net weekly income of less than $£ 100$ (Newhaven Research, 2004). It is therefore clear that most unemployed people within the sample, and especially the long-term unemployed, were among Glasgow's poorest residents - the legacy of a disempowering benefits system that provides little by way of disposable income while meeting housing costs through passported, means-tested benefits. As Gallie et al. (2003: 28) note, it may be that 'unemployment heightens the risk of people falling into poverty, and poverty in turn makes it more difficult for people to return to work'.

\section{Discussion: social inclusion, social networks and unemployment - is there a role for social policy?}

Given the findings discussed above, the question arises as to what role social policy can play in promoting both strengthened networks among the unemployed and social capital building in disadvantaged areas. There is some evidence that policy makers are increasingly focusing on the relationship between social capital and employability. At the time of the research, 'micro-neighbourhoods' in Glasgow were being targeted by a local authority-led 'Full Employment Areas Initiative', which deployed (among other approaches) teams of 'community animators' with a specific remit to build trust and relationships within communities 'street by street' and facilitate the development of social networks based around looking for, or even just thinking about, work. Initial evidence suggests that the strategy has been effective, at least in terms of engaging disadvantaged people who would not otherwise have been reached by 'traditional' services (Turok, 2007). Elsewhere in the UK, employability initiatives such as 'Working Neighbourhoods' and 'City Strategies' have sought to integrate supply-side labour market policies with measures to promote community interaction and social engagement within disadvantaged areas (Lindsay et al., 2007).

In more general terms, social capital building has become as a key concept in promoting regeneration and jobs growth in cities, so that 'it is increasingly hard to draw the line between "economic" and "social" aspects of regeneration' (Kleinman, 2000: 57). In the UK, both national and devolved governments have sought to link ideas around social capital and neighbourhood renewal with policies to promote employability - often 
explicitly noting that people in disadvantaged areas can be cut off from effective job search networks (SEU, 2001; Communities Scotland, 2002). Regional development agencies have also prioritised growing social capital as an objective for their intermediate labour market initiatives and community development programmes (Miles and Tully, 2007). Policies in Australia and Canada have similarly sought to encourage both individual employability and community development through social capital building initiatives (Gyarmati and Kyte, 2003; Kilpatrick, 2003).

These ideas are reflected in an emerging policy literature on 'attachment to place', employability and regeneration, which has sought to make links between social networking, community cohesion and experiences of socio-economic exclusion. Drawing on research with unemployed young people, Green and White (2007) argue that locally targeted initiatives to promote the expansion of networks - including social activities designed to enhance confidence, broaden spatial horizons, and raise awareness of routes into employment - can add value. Their research in urban communities in England highlights the manner in which young people's existing (mostly close knit) networks can be an important source of knowledge about jobs, but that they can also act as a brake by undermining confidence and discouraging take-up of certain opportunities. Gore et al.'s (2007) research in ex-coalfields areas explicitly links the geographically restricted social networks of some job seekers with problems in ensuring that neighbouring cities' economic growth impacts on employability and employment in former mining communities. They argue for localised initiatives to encourage networking between people in former coalfields and urban centres of employment.

These and other studies, and the evidence presented above, suggest that policy interventions focusing on alleviating the social impacts of long-term unemployment may be justified. However, there are dangers in seeing policies to promote social capital building as a panacea for area-based social exclusion. Crucially, an emphasis on the social aspects of employability should not be allowed to detract from the need for 'hard' economic regeneration in inner cities. In the US context, social capital building, as part of approaches to economic regeneration that call for bottom-up action and community self-improvement, has too often been seen by some as an alternative to the expansion (or maintenance) of state intervention. From this perspective: 'the poor and powerless are disadvantaged because they don't have enough (social) capital, but they can increase their 'stock' by becoming more competitive, hard-working and disciplined' (Mayer, 2003: 126). But this call for community self-reliance as a route to inclusion has been undermined by the harsh realities - that there are insufficient human and financial resources for disadvantaged communities to 'look after themselves', and that the local interventions that flow from such an approach are inherently fragmented, in both spatial and institutional terms (Merrett, 2001).

Reflecting on these issues, Maloney et al. (2000) have persuasively argued for an acknowledgment of the role of social policy (and especially collaboration between civil society and local/regional government) in strengthening the capacity of local stakeholders to generate social capital, but also for initiatives on social capital building to be linked with robust economic regeneration investment. The reality is that while policy interventions to re-connect people in disadvantaged areas with the world of work are justified, they must form part of broader strategies to promote economic development and decent jobs in inner cities, and address the full range of barriers experienced by the unemployed. Indeed, as Miles and Tully (2007) note, while key stakeholders working in deprived communities 
in the UK have acknowledged the potential value of efforts to build social capital and expand networks among the disadvantaged, there remains a concern that positive impacts will be limited if the right kind of jobs are not available at the end of the process.

\section{Conclusions}

Restricted access to social networks can impact on individuals' progress in the labour market. Restricted access to other forms of socially fulfilling interactions - the tertiary sphere of sociability - can impact on individuals' sense of isolation and ability to build networks and maintain relationships. This research sought to explore the extent to which long-term unemployed people are disadvantaged in terms of access to these forms of social capital. We have seen that many long-term unemployed people had restricted job search networks, so that personal contacts were relatively rarely used to look for work, and (in some cases) those contacts who were used were themselves unemployed. The research also demonstrates how long-term unemployment can reinforce exclusion from the tertiary sphere of sociability, as people increasingly withdraw from both informal socialising and organised community activities - this may in part reflect some of the characteristics of long-term unemployed people, who were (for example) initially more likely to live alone; but may also reflect the effects of a benefits system that imposes a sharp decline in income on many job seekers.

The research also sought to discuss the potential role of social policy in addressing these issues. The findings appear to strengthen the case for targeted interventions - for example, in the shape of local centres providing a focal point for community activities and opportunities for social engagement alongside employability services. Linking policy initiatives on social networking, community cohesion and employability makes sense given the potential importance of personal contacts to job search success. There may also be benefits associated with helping long-term unemployed people to access peer support and expand social networks, linked to the broadening of spatial horizons (Green and White, 2007), increasing awareness of a wider range of job opportunities (McQuaid and Lindsay, 2002) and (crucially) promoting social inclusion and psychological wellbeing (Gallie et al., 2003).

However, there is also need for holistic solutions that address the full range of individual skills deficits, personal and family circumstances and external factors that can act as barriers to work for the long-term unemployed. The long-term unemployed people participating in this research were more likely to have gaps in skills and qualifications, reported very low household incomes, and often had a range of health-related and other barriers to work. Nevertheless, the lack of potentially useful job search networks and the more general sense of isolation experienced by many long-term unemployed people (and some other vulnerable job seekers) clearly have the potential to reinforce and exacerbate these problems and resulting processes of social and labour market exclusion.

Long-term unemployed people and other vulnerable job seekers may benefit from an intensification of local strategies combining employability services that contribute to human capital development with opportunities for community engagement and social interaction. But the analysis above shows that any targeted policy initiatives need to reflect the complex range of inter-related barriers faced by long-term unemployed people and other job seekers. The challenge for policy makers is to help people in disadvantaged urban 
areas to address the 'network poverty' and social isolation that are an important dimension of the exclusion associated with the experience of long-term unemployment. Communitybased interventions to promote social capital cannot substitute for robust strategies to support economic development, promote jobs growth in depressed economies or reform a benefits system that often largely fails to alleviate poverty, but nor should the social element of the exclusion experienced by disadvantaged people and places be ignored.

\section{Notes}

1 Throughout, this article uses the 'ILO definition' of long-term unemployment - out of work and available for work for twelve months or more.

2 There are inherent problems in drawing a sample only from 'claimant' job seekers (those 'signing on' as actively seeking work and, in most cases, claiming Jobseeker's Allowance). There is strong evidence that many long-term unemployed men in particular claim sickness-related benefits and therefore do not appear in official unemployment statistics. Furthermore, as unemployment benefits, including Jobseeker's Allowance, have traditionally been claimed on behalf of households rather than as an individual right, women are under-represented in the official unemployed claimant count. Nevertheless, while acknowledging the problem of unemployment hidden as sickness, we should not ignore the barriers to work faced by those who are 'officially' long-term unemployed.

3 Among long-term unemployed job seekers, women were significantly more likely to report using work-based social networks to look for work on a regular basis, although the small numbers within this subsample should be noted. In the remainder of the analysis to follow, no statistically significant differences were apparent between men and women.

4 Source: Census 2001.

\section{References}

Beatty, C., Fothergill, S., Gore, T. and Powell, R. (2007), The Real Level of Unemployment, Sheffield: Sheffield Hallam University.

Chapple, K. (2002), 'I name it and I claim it, in the name of Jesus, this job is mine: job search, networks, and careers for low-income women', Economic Development Quarterly, 16, 4, 294313.

Clasen, J., Gould, A. and Vincent, J. (1997), Long-term Unemployment and the Threat of Social Exclusion, Bristol: Policy Press.

Communities Scotland (2002), Community Regeneration and Neighbourhood Renewal: A Review of Evidence, Edinburgh: Communities Scotland.

Fugate, M., Kinicki, A. and Ashforth, B. (2004), 'Employability: a psycho-social construct, its dimensions, and applications', Journal of Vocational Behavior, 65, 1, 14-38.

Gallie, D., Paugam, S. and Jacobs, S. (2003), 'Unemployment, poverty and social isolation: is there a vicious circle of social exclusion?', European Societies, 5, 1, 1-32.

Gore, T., Fothergill, S., Hollywood, E., Lindsay, C., Morgan, K., Powell, R. and Upton, S. (2007), Coalfields and Neighbouring Cities: Economic Regeneration, Labour Markets and Governance, York: Joseph Rowntree Foundation.

Granovetter, M. (1973), 'The strength of weak ties', American Journal of Sociology, 78, 6, 1360-80.

Granovetter, M. (1982), 'The strength of weak ties: a network theory revisited', in P. Marsden and N. Lin (eds.), Social Structure and Network Analysis, London: Sage.

Green, A. and Owen, D. (2006), The Geography of Poor Skills and Access to Work, York: Joseph Rowntree Foundation. 
Green, A. and White, R. (2007), Attachment to Place: Social Networks, Mobility and Prospects of Young People, York: Joseph Rowntree Foundation.

Gyarmati, D. and Kyte, D. (2003), 'Social capital, network formation and the community employment innovation project', Horizons, 6, 3, 19-24.

Hannan, C. (1999), Beyond Networks: Social Cohesion and Unemployment Exit Rates, Colchester: Institute for Social and Economic Research.

Hedstrom, P., Kolm, A. and Aberg, Y. (2003), Social Interactions and Unemployment, Stockholm: Institute for Labour Market Policy Evaluation.

Holzer, H. (1988), 'Search methods used by unemployed youths', Journal of Labor Economics, 6, 1, 1-20.

Julkunen, I. (2002), 'Social and material deprivation among unemployed youth in Northern Europe', Social Policy and Administration, 36, 3, 235-53.

Kilpatrick, S. (2003), The Role of VET in Building Social Capital for Rural Community Development in Australia, Launceston: University of Tasmania.

Kleinmann, M. (2000), 'Include me out? The new politics of place and poverty', Policy Studies, 21, 1, 49-61.

Lai, G., Lin, N. and Leung, S. (1998), 'Network resources, contact resources and status attainment', Social Networks, 20, 2, 159-78.

Lévesque, M. and White, D. (2001), 'Capital social, capital humain et sortie de l'aide sociale pour des prestataires de longue durée', Canadian Journal of Sociology, 26, 2, 167-92.

Lindsay, C., Greig, M. and McQuaid, R. W. (2005), 'Alternative job search strategies in remote rural and peri-urban areas: the role of social networks', Sociologia Ruralis, 45, 1, 53-70.

Lindsay, C., McQuaid, R. W. and Dutton, M. (2007), 'New approaches to employability in the UK: combining "Human Capital Development" and "Work First' approaches", Journal of Social Policy, 36, 4, 539-60.

MacDonald, R., Shildrick, T., Webster, C. and Simpson, D. (2005), 'Growing up in poor neighbourhoods: the significance of class and place in the extended transitions of "socially excluded" young adults', Sociology, 39, 5, 873-91.

McPherson, M., Smith-Lovin, L. and Cook, J. (2001), 'Birds of a feather: homophily in social networks', Annual Review of Sociology, 27, 415-44.

McQuaid, R. W. and Lindsay, C. (2002), 'The employability gap: long-term unemployment and barriers to work in buoyant labour markets', Environment and Planning C: Government and Policy, 20, 4, 613-29.

McQuaid, R. W. and Lindsay, C. (2005), 'The concept of employability', Urban Studies, 42, 2, $197-$ 219.

Maloney, W., Smith, G. and Stoker, G. (2000), 'Social capital and urban governance: adding a more contextualized top-down perspective', Political Studies, 48, 4, 802-20.

Mayer, M. (2003), 'The onward sweep of social capital: causes and consequences for understanding cities, communities and urban movements', International Journal of Urban and Regional Research, 27, 1, $110-32$.

Merrett, C. (2001), 'Declining social capital and non-profit organizations: consequences for small towns after welfare reform', Urban Geography, 22, 5, 407-23.

Miles, N. and Tully, J. (2007), 'Regional Development Agency policy to tackle economic exclusion? The role of social capital in distressed communities', Regional Studies, 41, 6, 855-66.

Mouw, T. (2003), 'Social capital and finding a job: do contacts matter?', American Sociological Review, $68,6,868-98$.

Newhaven Research (2004), Scottish House Condition Survey: Glasgow Report, Edinburgh: Communities Scotland.

Ooka, E. and Wellman, B. (2006), 'Does social capital pay off more within or between groups? Analysing job searches in five Toronto ethnic groups', in E. Fong (ed.), Inside the Mosaic, Toronto: University of Toronto Press.

Perri 6 (1997), Escaping Poverty: From Safety Nets to Networks of Opportunity, London: DEMOS. 
Reingold, D. (1999), 'Social networks and the employment problem of the urban poor', Urban Studies 36, 11, 1907-32.

SEU (Social Exclusion Unit) (2001), A New Commitment to Neighbourhood Renewal, London: Cabinet Office.

Sinfield, A. (1968), The Long-Term Unemployed - A Comparative Survey, Paris: OECD.

Sinfield, A. (1981), What Unemployment Means, Oxford: Martin Robertson.

Turok, I. (2007), Full Employment Strategies for Cities: The Case of Glasgow, Paris: OECD.

Wilson, W. (1996), When Work Disappears, New York: Albert A. Knopf. 